\title{
Syncope; the Initial Manifestation of Pulmonary Embolism: A Case Report
}

\author{
Hassan Ahangar1 $^{\text {(D) }}$, Helia Pournaghshband ${ }^{2}$ (D) Hanieh Paydari $^{3}$ (D), Ali Niksirat ${ }^{* 4}$ (D) \\ 1. Dept. of Cardiology, Faculty of Medicine, Zanjan University of Medical Sciences, Zanjan, Iran \\ 2. Faculty of Medicine, Iran University of Medical Sciences, Tehran, Iran \\ 3. Faculty of Medicine, Tehran University of Medical Sciences, Tehran, Iran \\ 4. Dept. of Internal Medicine, Imam Khomeini Hospital Complex, Tehran University of Medical Sciences, Tehran, Iran
}

\begin{tabular}{|c|c|}
\hline Article Info & ABSTRACT \\
\hline dol $10.30699 / j a m b s .26 .119 .48$ & \multirow{3}{*}{$\begin{array}{l}\text { Syncope is the state of lack of consciousness and temporal loss of postural tone. } \\
\text { Syncope might be in association with a variety of benign and life-threatening } \\
\text { conditions. Pulmonary embolism (PE) has been shown to be associated with syncope } \\
\text { in } 13-30 \text { percent of cases. This article presents a novel case report of PE whose only } \\
\text { manifestation was syncope. } \\
\text { Keywords: Consciousness, Syncope, Pulmonary Embolism, }\end{array}$} \\
\hline $\begin{array}{c}\text { Received: 2017/10/18; } \\
\text { Accepted: 2018/06/07; } \\
\text { Published Online: 01 Nov 2018; }\end{array}$ & \\
\hline $\begin{array}{l}\text { Corresponding Information: } \\
\text { Ali Niksirat, } \\
\text { Dept.of Internal Medicine, Imam Khomeini } \\
\text { Hospital Complex, Tehran University of } \\
\text { Medical Sciences, Tehran, Iran } \\
\text { Email: ali.niksirat@yahoo.com }\end{array}$ & \\
\hline 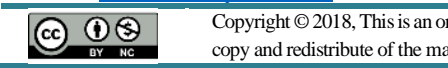 & $\begin{array}{l}\text { pen-access article distributed under the terms of the Creative Commons Attribution-noncommercial } 4.0 \text { International License which permits } \\
\text { st in noncommercial usages with proper citation. }\end{array}$ \\
\hline
\end{tabular}

\section{Introduction}

Syncope is the state of lack of consciousness and temporal loss of postural tone. The patient promptly recovers and gains complete consciousness soon after (1).

Syncope might be in association with a variety of benign and life-threatening conditions (1). Due to this, health care clinicians must rule out the common lifethreatening causes such as structural heart diseases and arrhythmias (2).

Pulmonary Embolism (PE) is a deviation of Venous Thromboembolism (VTE), and might be the underlying condition causing syncope. The acute form of PE is the most serious complication among different clinical presentations of VTE (3).

In some cases, $\mathrm{PE}$ is difficult to diagnose promptly due to its non-specific clinical presentation. Most commonly, the suspicion of PE is raised by unexplained chest pain, dyspnea, hemoptysis, and pre-syncope or syncope (4).

Due to the lack of treatment, death rate is estimated at about $30 \%$, which can be reduced to $2-8 \%$ with immediate and appropriate treatment (5).

Obesity, surgery, prolonged physical inactivity (hospitalization, bed rest, etc.), usage of oral contraceptives in fertile women, neoplasms, and pregnancy are believed to be associated with the occurrence of PE (2). PE has been associated with syncope in $13-30 \%$ of cases (6).

Although the etiology is still not clear, syncope is thought to be associated with three mechanisms in patients with acute PE (2).
1.Normally, a right ventricular (RV) failure caused by the occlusion of more than $50 \%$ of the pulmonary vascular tree can lead to an increase in the RV filling pressure and lead to a decreased stroke volume and cerebral blood flow (2).

2.In case of a pulmonary embolism, bradyarrhythmias and tachyarrhythmias, which are caused by hemodynamic alterations and an overload of the right ventricle, might also be a cause of syncope (7).

3.PE can also trigger a vasovagal reflex leading to syncope (8).

Treatment of an acute pulmonary emboli includes treatment e.g. vasopressors, as well as pharmacological, interventional, or surgical reperfusion (3), anticoagulation (parenteral anticoagulation (3, 9), Vitamin K agonists (3, 10) and new oral anticoagulants known as non-vitamin $K$ dependent new anticoagulants- NOACs. Some examples of this group of medications are: Dabigratan, Rivaroxaban, Apixaban, Edoxaban (3). Thrombolytic treatment (11), Surgical embolectomy $(3,12)$, Percutaneous catheterdirected treatment $(3)$, Venous filters $(13,14)$ and other treatment strategies are to be mentioned as well (3).

The following case report shows the importance for the consideration of PE when addressing syncope as it represents the massiveness of embolism in most cases.

\section{Case Report}

Patient is a 38 -year-old male admitted to the ER (Emergency Room) complaining of 3 attacks of transient loss of consciousness for four days. The 
patient mentioned that upon rising and walking for only a few steps (2-3), he lost consciousness and fell without having any prodromal symptoms, which lead to frontal area trauma. After about a minute, the patient regained consciousness and gained alertness without any therapeutic intervention. $\mathrm{He}$ did not experience complications of vertigo, dizziness, or amnesia. His first and second attacks were not accompanied by physical injury but there was frontal area trauma while the patient's third attack happened, which led him to go to the Emergency Room (ER).

He did not have any complaints of nausea, vomiting, palpitation, dyspnea, sweating, or urinary and stool incontinence. There was no evidence of tongue biting or tonic-clonic movement. While at the ER, he did not experience dyspnea or chest pain. There was no history of IHD (Ischemic Heart Disease), DM (Diabetes Mellitus), HTN (Hypertension), or hyperlipidemia. His smoking history was negative. He was not using any medications and no major surgical procedure had been performed on him prior to admission. Approximately 40 days ago, the patient had fallen from a location 1.5 meters in height, which resulted in a left foot internal malleolus fracture that eventuated to a short cast, causing limited activity. The patient had no family history of syncope, sudden cardiac death, or seizure.

He did not have orthostatic hypotension and vital signs were normal. $\mathrm{His}_{2}$ saturation was $96 \%$.

There was a small, non-bleeding non-perforated 2-3 $\mathrm{cm}$ ulcer in the frontal area. Jugular Venous Pulse (JVP) was normal. S1 and S2 sounds were normal. A systolic murmur with the intensity of II/VI was audible at the site of left lower sternal border. Auscultation of the lungs was clear and normal. The neurologic exam was normal, without focal neurologic deficit and an intact central and peripheral cranial nerves. Blood tests and cardiac markers were marked at normal range.

The CT scan of the brain was normal, without any evidence of either space occupying lesion (SOL), hemorrhage, or ischemia. The X-ray of the chest was normal. Cardiac markers and an electrocardiogram (ECG) were requested for the patient due to the suspicion of acute coronary syndrome (ACS). His ECG showed sinus tachycardia, right axis deviation, a S1Q3T3 pattern, and a prominent $\mathrm{R}$ wave in $\mathrm{V} 1$ lead (Figure1). The serial cardiac marker did not show an increase.

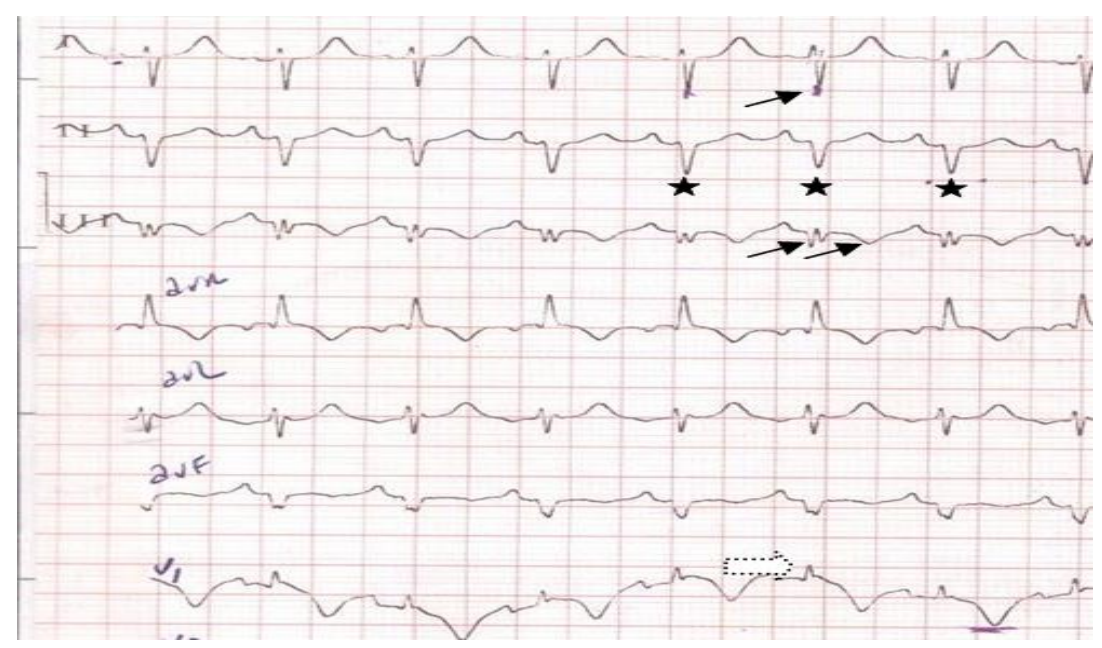

Figure 1. Patient's EKG on admission

[EKG shows sinus tachycardia (stars), Right Axis deviation, S1Q3T3 pattern (black arrows) and prominent $R$ wave in $V 1$ (dashed arrow)]

The transthoracic echocardiography showed abnormal LV (Left Ventricle) size and function (LVEF: 55\%), while the RV (Right Ventricle) was enlarged significantly. There was a displacement of the intraventricular septum towards the left ventricle. Moderate hypokinesia of the RV free wall was present. The apex was spared (McConnell's sign). A suspicious clot was seen dilated in the main pulmonary artery during bifurcation, and Tricuspid Regurgitation (TR) was present with Peak Pressure Gradient (PG) of 45 $\mathrm{mmHg}$ and dilated Inferior Vena Cava (IVC). The estimated Pulmonary Arterial Pressure (PAP) was 50$55 \mathrm{mmHg}$. There was no evidence of thrombosis on the venous ultrasound performed on the left lower extremity and pelvis while searching for a primary source for PE. A multi-slice pulmonary CT angiography showed a large filing defect at PA bifurcation with an extension to the right and left PA, suggesting a saddle pulmonary embolus. Although his blood pressure was well-preserved, we decided to put him on thrombolytics based on our findings. Streptokinase (SK) was the available choice, and thus, it was selected with a 250,000 unit IV in a 60-minute infusion, followed by $100,000 \mathrm{U} / \mathrm{h}$. This went on for 24 hours. At this stage, it was nearly 6 days since the symptoms first started. The patient showed a dramatic clinical and preclinical response to thrombolytic therapy. On the second day, tachycardia was reduced 
markedly. The ECG showed the elimination of the deep $S$ wave in lead I and the deviation of the axis from right to left. The right ventricle improved in global function and there was a decrease in PAP (from 50-55 mmHg to 20-25 mmHg) (Figure 2). Unfractionated heparin (UFH) began with 18 units $/ \mathrm{kg} /$ hour intravenously and titrated by the control of PTT.
Our patient got discharged in a good status. He displayed no evidence of syncope with his prescribed warfarin $(5 \mathrm{mg} /$ daily) with a target INR of $2-3$. He was visited by us once a week at the clinic for a month. He remained symptom-free and the function of the right ventricle continued to be normal. The patient will be on anticoagulants with full intensity for up to 6 months and there will be monthly follow-ups.

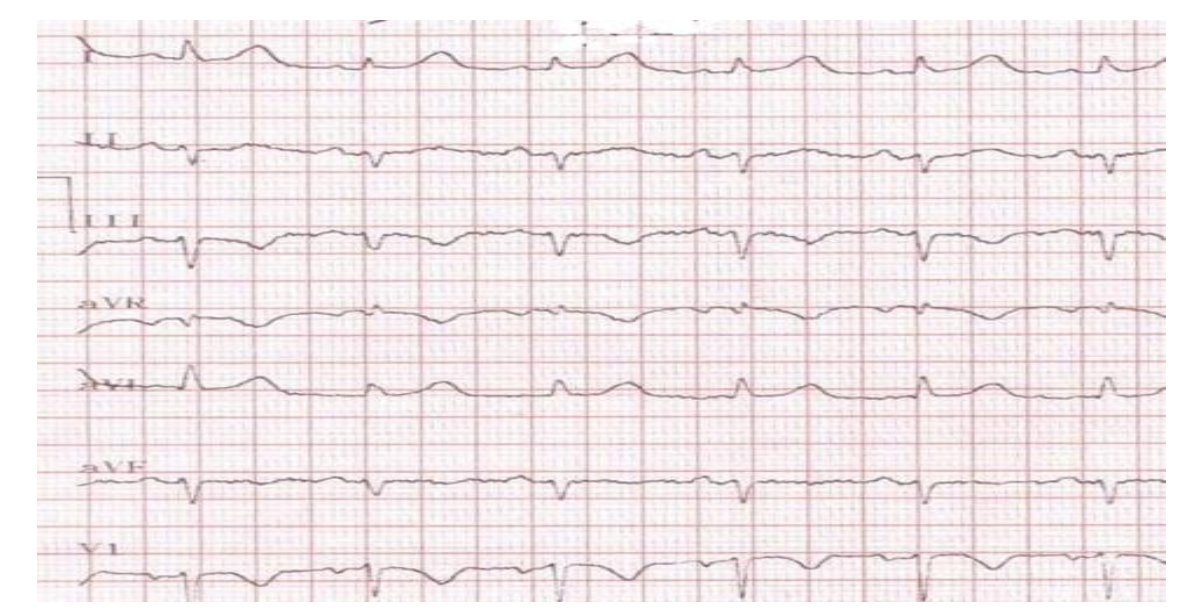

Figure 2. Patient's EKG after thrombolytic therapy (EKG shows normal sinus rhythm, Left Axis deviation and elimination of Right Axis deviation)

\section{Discussion}

At times, pulmonary embolism is not an easy diagnosis due to the great variety of its clinical presentations. Most patients suffering from pulmonary embolism display one of the three clinical pictures, which raises suspicion to acute pulmonary embolism which contains unexplained acute dyspnea, pleuritic chest pain, and hemoptysis. However, the triad of these symptoms is rarely found in patients with PE. Syncope is rare (13-30 percent of cases) and quite difficult to relate to the condition of pulmonary embolism. Syncope is an easy presentation to be noticed, but its etiology cannot be easily determined.

Our patient did not show any common manifestation of massive pulmonary emboli and had normal results in routine diagnostic tests such as a chest X-ray, an $\mathrm{O}_{2}$ saturation, and without any relevant clinical history or symptoms. The only presentation of our patient was the occurrence of syncope, which made it even more difficult to properly diagnose.

In case of a PE suspicion, the first step of the clinician is to search for hypotension, tachyarrhythmia, bradycardia, hemodynamic changes, and other relative signs and symptoms. These are symptoms which our patient lacked.

EKG and X-Rays are often reported to be normal, whereas pulse $\mathrm{O}_{2}$ saturation is usually dropped.

The EKG of our patient showed sinus tachycardia, right axis deviation, S1Q3T3 pattern, and prominent $\mathrm{R}$ wave in $\mathrm{V} 1 . \mathrm{O}_{2}$ saturation was normal.
Despite the normal blood pressure, antithrombotic agents were prescribed due to right ventricular free wall Hypokinesia. Some other indications for the use of thrombolytic agents are: ST elevation, arterial thrombosis, myocardial infarction, deep vein thrombosis, etc. (15).

In a study performed by Seyyedi et al., the prevalence of patients with PTE presentation of syncope was reported to be $11.1 \%$, which confirms the rarity of this manifestation in PE (16). It has been mentioned in Stein PD. et al.'s study that normal ABG and A-a gradient do not rule out pulmonary embolism, as seen in this report as well (17).

\section{Conclusion}

PTE might occur with a presentation of syncope as its only manifestation. It is of great importance to consider PE as a differential diagnosis. Other routine presentations of PE may be absent and the symptoms can be misleading. The initial manifestation of PE is rarely presented as syncope, and thus, the prognosis of the patient depends on an early and proper diagnosis and treatment. In this study, it can be concluded that despite classical symptoms of PTE and additional underlying conditions as absent, PE must be ruled out in every patient with syncope presentation of an unknown etiology,

\section{Acknowledgements}

The authors thank all those who helped them writing this paper. 


\section{Conflict of Interest}

Authors declare no conflict of interests.

\section{References}

1. Lempert T, Bauer M, Schmidt D. Syncope: a videometric analysis of 56 episodes of transient cerebral hypoxia. Ann Neurol. 1994; 36(2): 233-7. [DOI:10.1002/ana.410360217] [PMID]

2. Dipaola F, Cucchi I, Filardo N, et al. Syncope as a symptom of non-massive pulmonary embolism: a case report. Intern

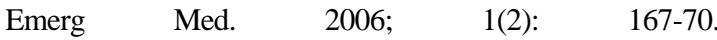
[DOI:10.1007/BF02936550] [PMID]

3. Konstantinides SV, Torbicki A, Agnelli G, et al. 2014 ESC guidelines on the diagnosis and management of acute pulmonary embolism. Eur Heart J. 2014; 35(43): 3033-69. [DOI:10.1093/eurheartj/ehu283] [PMID]

4. Pollack CV, Schreiber D, Goldhaber SZ, et al. Clinical characteristics, management, and outcomes of patients diagnosed with acute pulmonary embolism in the emergency department: initial report of EMPEROR (Multicenter Emergency Medicine Pulmonary Embolism in the Real World Registry). J Am Coll Cardiol. 2011; 57(6): 700-6. [DOI:10.1016/j.jacc.2010.05.071] [PMID]

5. Torbicki A, Perrier A, Konstantinides s, et al. Guidelines on diagnosis and management of acute pulmonary embolism. Task Force on Pulmonary Embolism, European Society of Cardiology. Eur Heart J. 2000; 21(16): 1301-36. [DOI:10.1053/euhj.2000.2250] [PMID]

6. Jimenez D, Diaz G, Valle M, et al. Prognostic value of syncope in the presentation of pulmonary embolis. Arch Bronconeumol. 2005; 41(7): 385-8. [DOI:10.1016/S15792129(06)60246-2]

7. Demircan A, Aygencel G, Keles A, Ozsoylar O, Bildik F. Pulmonary embolism presenting as syncope: a case report. J Med Case Rep. 2009; 3: 7440. [DOI:10.4076/1752-1947-37440] [PMID] [PMCID]

8. Rafighdoust AA, Tayebi M, Pourzand H. Syncope as the Clinical Presentation of Pulmonary Thromboembolism. The Univ Heart Ctr. 2007; 2(1): 49-53.

9. Cossette B, Pelletier ME, Carrier N, et al. Evaluation of bleeding risk in patients exposed to therapeutic unfractionated or low-molecular-weight heparin: a cohort study in the context of a quality improvement initiative. Ann Pharmacother. 2010; 44(6): 994-1002. [DOI:10.1345/aph.1M615] [PMID]

10. De Caterina R, Husted S, Wallentin L, et al. Vitamin K antagonists in heart disease: current status and perspectives (Section III). Position paper of the ESC Working Group on Thrombosis--Task Force on Anticoagulants in Heart Disease. Thromb Haemost. 2013; 110(6): 1087-107. [DOI:10.1160/TH13-06-0443] [PMID]

11. Becattini C, Agnelli G, Salvi A, et al. Bolus tenecteplase for right ventricle dysfunction in hemodynamically stable patients with pulmonary embolism. Thromb Res. 2010; 125(3): 82-6. [DOI:10.1016/j.thromres.2009.09.017] [PMID]

12. Kilic A, Shah AS, Conte JV, Yuh DD. Nationwide outcomes of surgical embolectomy for acute pulmonary embolism. J Thorac Cardiovasc Surg. 2013; 145(2): 373-7. [DOI:10.1016/j.jtcvs.2012.01.066] [PMID]

13. Stein PD, Matta F, Keyes DC, Willyerd GL. Impact of vena cava filters on in-hospital case fatality rate from pulmonary embolism. Am J Med. 2012; 125(5): 478-84. [DOI:10.1016/j.amjmed.2011.05.025] [PMID]

14. Muriel A, Jimenez D, Aujesky D, et al. Survival effects of inferior vena cava filter in patients with acute symptomatic venous thromboembolism and a significant bleeding risk. J Am Coll Cardiol. 2014; 63(16): 1675-83. [DOI:10.1016/j.jacc.2014.01.058] [PMID]

15. Wiener C, Fauci AS, Braunwald E, et al. Harrison's principles of internal medicine, self-assessment and board review: McGraw Hill Professional; 2008.

16. Seyyedi SR, Jenab Y, Tokaldany ML et al. Syncope paradox in the outcome of patients with pulmonary thromboembolism: short-term and midterm outcome. Clin Respir J. 2016; 10(1): 90-7. [DOI:10.1111/crj.12183] [PMID]

17. Stein PD, Terrin ML, Hales CA, et al. Clinical, laboratory, roentgenographic, and electrocardiographic findings in patients with acute pulmonary embolism and no pre-existing cardiac or pulmonary disease. Chest. 1991; 100: 598-603. [DOI:10.1378/chest.100.3.598]

\section{How to Cite This Article:}

Ahangar H, Pournaghshband H, Paydari H, Niksirat A. Syncope; the Initial Manifestation of Pulmonary Embolism: A Case Report. J Adv Med Biomed Res. 2018; 26 (119) :47-50

\section{Download citation:

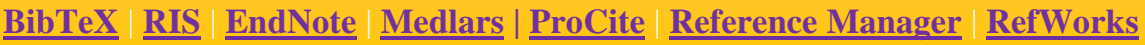 \\ Send citation to: \\ Mendeley $2 \underline{\text { Zotero }}$ (i) RefWorks $\underline{\text { RefWorks }}$}

